\title{
Respiratory function measurements in a cohort of medical students: a ten-year follow-up
}

\author{
P J LAWTHER, A G F BROOKS, AND R E WALLER \\ From the MRC Toxicology Unit (Clinical Section), St Bartholomew's Hospital Medical College, \\ London ECIM 6BQ, UK
}

Lawther, P J, Brooks, A G F, and Waller, R E (1978). Thorax, 33, 773-778. Respiratory function measurements in a cohort of medical students: a ten-year follow-up. A cohort of medical students first seen in 1962 has now been examined for a third time. The prevalence of symptoms of cough, phlegm, and breathlessness among them has remained low, and smoking habits have been light in comparison with those of the general population. Results of the three successive sets of measurements of lung function indicate that, in general, optimum values were reached in the early 20 s, with little further change up to age 29 . There was some evidence of reduced ventilatory capacity in subjects with histories of acute chest illnesses.

Much of the published information on the rate of change of lung function with age (Cotes, 1975) is derived from the results of cross-sectional studies in which people of different ages have been examined on one occasion only. While such data are adequate for clinical purposes, providing normal values against which to assess observations made on patients, they do not necessarily indicate the true rate of change within individuals. In recent years much attention has been given to this point, and information is gradually being accumulated on the rate of change both within individuals (Fletcher et al, 1976) and within population groups followed on a longitudinal basis (Howard, 1970; Ferris et al, 1976; Kauffman et al, 1976; Oxhoj et al, 1976). The indications so far are that beyond the early adult years, the rate of change of ventilatory function (in terms of forced expiratory volume in one second $\left(\mathrm{FEV}_{1}\right)$ or forced vital capacity (FVC)) with age is not substantially different from that determined from cross-sectional studies (Cotes, 1976). There is, however, relatively little information on the rate of change within the early adult years, covering the period when most lung function values reach their maxima.

The study that we report here was started in 1962 to investigate the feasibility of following changes in a wide range of lung function measurements, and in respiratory symptoms, on a longitudinal basis from early adult ages onwards. It was on a small scale, but one feature was that all the subjects were in a narrow age-range, being medical students in the first year of their course at our medical college. The measurements were repeated towards the end of their course, and it was shown then that there was a tendency for most of the measurements of lung function examined to improve slightly over the age range 19 to 23 (Lawther et al, 1970). The present paper reports the situation six years later, when the average age of the subjects was 29 .

\section{Methods}

Initially 103 students agreed to co-operate in this study during their first year at the college, and by the time of the second examination, four years later, there were 92 survivors of the course, all of whom were seen. For the third examination in the series, arranged to be ten years after the initial one, all 92 were traced through the Medical Register and the college authorities. By then they were qualified medical practitioners dispersed over the whole of the UK, and some were abroad. In all, 62 of them were able to attend the laboratory for examination, and a further 13 returned selfadministered questionnaires.

The subjects made just one visit, at a time to suit their convenience, and we could not therefore ensure a uniform time of day for the respiratory function measurements. They first answered the MRC questionnaire on respiratory symptoms (Medical Research Council, 1966), and care was taken to ensure uniformity with the procedure in 
the earlier visits, which had been based on the 1960 short version of the questionnaire. Some additional questions were asked about allergies and sporting activities. Most of the interviewing was again done by one person (PJL) and a clinical examination (heart and lungs) and measurements of height, weight, and blood pressure were included. The respiratory function tests were carried out in the same order as before, using the same techniques and the same type of apparatus (Lawther et al, 1970).

There were 50 men and 12 women in the group attending for the complete examination. All the available respiratory function results are included in the tables, with some minor exclusions where data were incomplete in the original series. Because records of FVC from the first series were incomplete (with many students exceeding the capacity of the spirometer bell originally used), FVC has been excluded in the comparisons now made, but VC is included. Replies from all 75 questionnaires were used to prepare tables on smoking habits and respiratory symptoms. The small proportion of self-administered questionnaires were accepted as being valid, along with those obtained with an interviewer.

\section{Results}

\section{SMOKING}

On entry to the college, the proportion of smokers among the students (men $30 \%$, women $10 \%$ ) was seen to be low compared with that in the general population. A small increase in smoking was reported at the time of the second examination, and little further change was seen by the time of the third visit. Table 1 summarises the position among the men, the number of women in the sample being too small to allow trends to be followed. Not only was the proportion of smokers lower in these subjects than in the general population, but the amount smoked was also less. Results from the most recent set of interviews showed some anomalies in the reporting of smoking histories: several subjects who had denied smoking on their first visit later said that they had smoked at the time. In general this was a case of omitting to mention smoking that had then been at a low level or of short duration.

\section{RESPIRATORY SYMPTOMS}

The prevalence of symptoms as assessed from the questionnaires is shown in table 2. This is restricted to the 75 subjects seen on all three occasions, and in view of the small numbers results for the two sexes have been combined. Only two subjects re-
Table 1 Smoking habits among men seen on three successive occasions

\begin{tabular}{llllll}
\hline & & Smokers \% & \multicolumn{2}{l}{$\begin{array}{l}\text { Cigarettes per day } \\
\text { per smoker }\end{array}$} \\
\cline { 3 - 6 } & No & $\begin{array}{l}\text { Student } \\
\text { cohort }\end{array}$ & $\begin{array}{l}\text { General } \\
\text { population }\end{array}$ & $\begin{array}{l}\text { Student } \\
\text { cohort }\end{array}$ & $\begin{array}{l}\text { General } \\
\text { population }\end{array}$ \\
\hline 1962-3, age 19 & 83 & 30 & 58 & $6 \cdot 2$ & $8 \cdot 1$ \\
$1966-7$, age 23 & 74 & 39 & 65 & $7 \cdot 6$ & $11 \cdot 4$ \\
$1972-3$, age 29 & 59 & 40 & 63 & $7 \cdot 1$ & $13 \cdot 3$ \\
\hline
\end{tabular}

The smoking categories include pipe and cigar smokers.

General population figures are for the years 1963, 1968, and 1973 respectively (tables $9 \mathrm{~m}$ and $14 \mathrm{~m}$, Lee, 1976).

Table 2 Prevalence of respiratory symptoms, men and women

\begin{tabular}{|c|c|c|c|c|}
\hline \multirow{2}{*}{$\begin{array}{l}\text { Question } \\
\text { no }\end{array}$} & \multirow[t]{2}{*}{ Symptoms } & \multicolumn{3}{|c|}{ Percentage positive } \\
\hline & & $\begin{array}{l}\text { General } \\
\text { population }\end{array}$ & $\begin{array}{l}\text { Student cohort } \\
1962-3 \quad 1967-8\end{array}$ & $1972-3$ \\
\hline
\end{tabular}

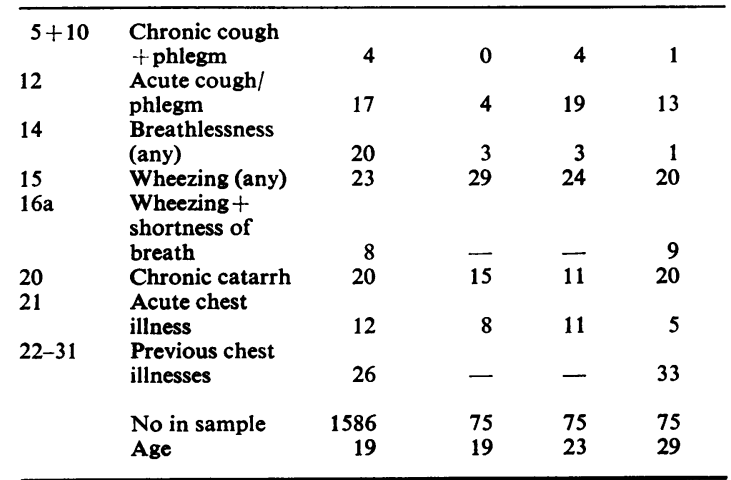

Question numbers relate to the 1966 version of the MRC questionnaire on respiratory symptoms. The general population results relate to a sample of Londoners seen in 1970-2 (Waller et al, 1975).

ported a regular cough of any kind when first seen, but by the second visit several reported chronic cough with production of phlegm: two of these had taken up smoking since the first visit. Results are compared with those obtained in a general population sample of Londoners aged 18 to $19 \%$ (Waller et al, 1975). The most notable contrast N is in the prevalence of breathlessness, which is low N throughout the present series, even if due account is taken of the low proportions of women and of smokers within it. In terms of episodes of acute respiratory illnesses, or of prevalence of wheezing $\stackrel{\oplus}{\rightleftharpoons}$ or catarrh, the group does not appear to differ substantially from the general population.

\section{RESPIRATORY FUNCTION}

Results from the respiratory function measurements made on the 47 men who attended the third examination are shown in table 3 , along with the

.


Table 3 Respiratory function measurements. Means (and standard deviations) for 47 men seen on three successive occasions

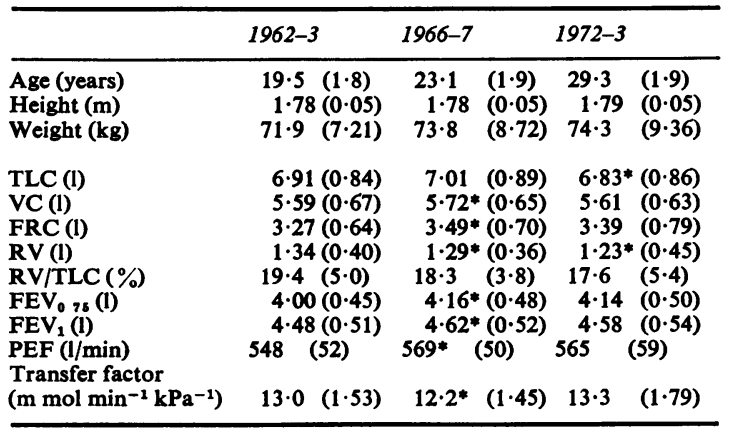

*Within-subject changes, as compared with preceding values, significant ( $P<0.05, t$ test).

Heights are quoted without shoes and weights in light clothes. Spirometric readings have been corrected to BTPS, and transfer factor to STPD.

mean values for the same subjects on their earlier visits. Changes in most of the lung function values throughout the decade covered were small, but the overall tendency was for a slight improvement from the first to the second set of measurements, with just the beginning of a decline with age appearing by the time of the third set. When assessed in terms of within-subjects differences, some of the changes were significant, even though they were of small magnitude. One unexpected finding was that the mean transfer factor declined from the first to the second occasion and then increased again by the third.

The number of women attending all three exam- inations (12) was too small to establish trends clearly, but the pattern was similar to that of the men. There was, however, no indication of any increase in peak flow from the first to the second visit, nor of any change in transfer factor.

A close correlation between readings on the first and second occasions had been found earlier for most measures of lung function, and this was maintained when the third observations were related to the second. To examine further the changes within individuals, scatter diagrams were plotted for each set of observations, and those for peak flow (men) are shown in the figure. It is clear from this that the general tendency was for subjects whose peak flow was already high by age 19 to change little by age 23 , while those with lower values changed more. The situation was more uniform over the next six years, with most subjects staying at about the same value.

Three of the subjects who were below the regression line relating second to first results (figure (a)) had histories of respiratory allergies, and a fourth was an older student who should strictly be excluded when results are considered on an age basis. There were three subjects whose peak flow had declined quite considerably from the second to the third visit, so as to fall well below the regression line (figure (b)), and each of them had reported some history of pneumonia or pleurisy.

Mean values for each of the lung function measurements were also calculated for all subjects reporting chest illnesses (bronchitis, pneumonia, pleurisy, or asthma) at any time from birth up to the third visit, and these are compared in table 4
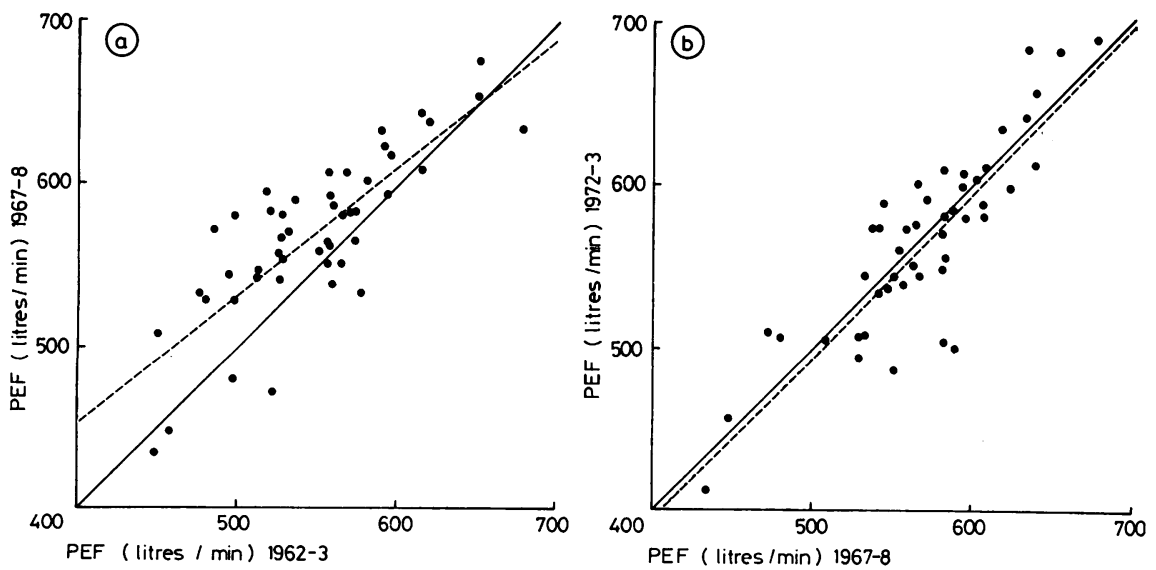

Figure Scatter diagrams showing relationships between peak flow readings (a) on first and second occasions, and (b) on second and third (men only). Dotted lines are regression lines $(y$ on $x)$ and solid ones are lines of equality. 
Table 4 Means (and standard deviations) for respiratory function values in relation to previous chest illnesses, and to cigarette smoking (men). Standardised to height of $1.74 \mathrm{~m}$

\begin{tabular}{|c|c|c|c|c|c|}
\hline & $\begin{array}{l}\text { No of } \\
\text { subjects }\end{array}$ & $\begin{array}{l}F E V_{1} \\
(l)\end{array}$ & $\begin{array}{l}M M F \\
\left(l / \sec ^{-1}\right)\end{array}$ & $\begin{array}{l}P E F \\
\left(l / \min ^{-1}\right)\end{array}$ & $\begin{array}{l}T F \\
\left(m \mathrm{~mol} \mathrm{~min}^{-1} \mathrm{kPa}^{-1}\right)\end{array}$ \\
\hline $\begin{array}{l}\text { Chest illnesses } \\
\text { No chest illnesses }\end{array}$ & $\begin{array}{l}18 \\
29\end{array}$ & $\begin{array}{l}4 \cdot 24(0.41) \\
4 \cdot 32(0.42)\end{array}$ & $\begin{array}{l}4.04(0.82) \\
4.45(1.13)\end{array}$ & $\begin{array}{l}534(52) \\
559(58)\end{array}$ & $\begin{array}{l}12 \cdot 8(1 \cdot 7) \\
12 \cdot 6(1 \cdot 6)\end{array}$ \\
\hline $\begin{array}{l}\text { Cigarette smokers } \\
\text { Others }\end{array}$ & $\begin{array}{l}13 \\
34\end{array}$ & $\begin{array}{l}4 \cdot 23(0 \cdot 52) \\
4 \cdot 32(0 \cdot 39)\end{array}$ & $\begin{array}{l}4 \cdot 21(0 \cdot 88) \\
4 \cdot 33(1 \cdot 10)\end{array}$ & $\begin{array}{l}541(58) \\
553(56)\end{array}$ & $\begin{array}{l}12 \cdot 3(1 \cdot 8) \\
12 \cdot 8(1 \cdot 5)\end{array}$ \\
\hline
\end{tabular}

None of the differences between pairs is significant at the $5 \%$ level in this table ( $t$ test).

with results for subjects without such symptoms. To avoid possible bias due to differences in height between members of the subgroups, these results were standardised to a height of $1.74 \mathrm{~m}$ (as in earlier studies: Brooks and Waller, 1972) using regression coefficients from the current series. Comparisons were also made between the results for cigarette smokers and others (as at the time of the third visit). Although none of the differences between these subgroups was statistically significant, there was at least an indication that a history of chest illness and cigarette smoking were both associated with reductions in ventilatory function, and the contrasts were most pronounced in the case of MMF in relation to chest illnesses.

The regression of each of the lung function values on height was considered for all the men at the time of the first examination, and it has been repeated now for the 47 who attended on the three successive occasions (table 5). For the main spirometric observations (VC, FEV 1 and MMF) the regression coefficients remained remarkably steady, but there was more scatter in these coefficients in the case of peak flow and transfer factor, and for these the correlation with height was relatively poor. The correlation between peak flow and height was seen to be appreciably reduced by the low readings for subjects who had reported respiratory allergies, and whose peak flow was liable to vary widely, even over short intervals.

Most of the regression coefficients have remained close to those quoted for other groups of subjects (Cotes, 1975), and the relatively steep slope seen in the case of $\mathrm{FEV}_{1}$ has been maintained throughout the series. There is evidence from other surveys (Lowe et al, 1968; Higgins and Keller, 1973) that this slope is steeper for young adults than for older groups, and Cole $(1974 ; 1975)$ has proposed improved models of the relationship between ventilatory capacity and height, taking into account the apparent age/height interaction.

OTHER OBSERVATIONS

Blood pressure was measured during the first and third examinations to provide baselines for long-
Table 5 Regression coefficients for respiratory function values on standing height (metres) for 47 men seen on three occasions. Equations of form $y=a+b x$

\begin{tabular}{|c|c|c|c|c|}
\hline & & $\begin{array}{l}\text { Constant } \\
a\end{array}$ & $\begin{array}{l}\text { Regression } \\
\text { coefficient } \\
b\end{array}$ & $\begin{array}{l}\text { Correlation } \\
\text { coefficient } \\
r\end{array}$ \\
\hline $\mathrm{VC}(1)$ & $\begin{array}{l}\text { 1st } \\
\text { 2nd } \\
3 r d\end{array}$ & $\begin{array}{l}-6 \cdot 84 \\
-6 \cdot 61 \\
-6.48\end{array}$ & $\begin{array}{l}6 \cdot 95 \\
6 \cdot 91 \\
6 \cdot 77\end{array}$ & $\begin{array}{l}0.49 \\
0.49 \\
0.50\end{array}$ \\
\hline $\mathrm{FEV}_{1}(1)$ & $\begin{array}{l}\text { 1st } \\
\text { 2nd } \\
3 r d\end{array}$ & $\begin{array}{l}-6.87 \\
-7.06 \\
-7.42\end{array}$ & $\begin{array}{l}6 \cdot 36 \\
6 \cdot 55 \\
6 \cdot 73\end{array}$ & $\begin{array}{l}0.59 \\
0.59 \\
0.59\end{array}$ \\
\hline $\operatorname{MMF}\left(1 / \sec ^{-1}\right)$ & $\begin{array}{l}1 \text { st } \\
\text { 2nd } \\
3 \text { rd }\end{array}$ & $\begin{array}{l}-\overline{12} \cdot 90 \\
-13 \cdot 73\end{array}$ & $\begin{array}{r}9.91 \\
10.36\end{array}$ & $\begin{array}{l}- \\
0.44 \\
0.42\end{array}$ \\
\hline $\operatorname{PEF}\left(1 / \mathrm{min}^{-1}\right)$ & $\begin{array}{l}1 \mathrm{st} \\
2 \mathrm{nd} \\
3 \mathrm{rd}\end{array}$ & $\begin{array}{r}-67 \\
211 \\
-15\end{array}$ & $\begin{array}{l}345 \\
201 \\
325\end{array}$ & $\begin{array}{l}0 \cdot 32 \\
0 \cdot 19 \\
0 \cdot 26\end{array}$ \\
\hline $\begin{array}{l}\text { TF (m mol } \\
\left.\min ^{-1} \mathrm{kPa}^{-1}\right)\end{array}$ & $\begin{array}{l}1 \text { st } \\
\text { 2nd } \\
\text { 3rd }\end{array}$ & $\begin{array}{r}-0.01 \\
-2.23 \\
-14.54\end{array}$ & $\begin{array}{r}7 \cdot 31 \\
8 \cdot 08 \\
15 \cdot 62\end{array}$ & $\begin{array}{l}0.23 \\
0.26 \\
0.42\end{array}$ \\
\hline
\end{tabular}

term follow-up. All were within normal limits for age (Hamilton et al, 1954), and the means were: first visit $M 118 / 77$, F 116/63; third visit M 116/ 75 , F $111 / 72$. Weights were measured on each occasion, primarily to examine inter-relationships with the lung function measurements. Within this series there was no significant correlation between any of the latter and weight once height had been taken into account. Among the subjects who attended all three examinations, there was a slight increase in the average weight of the men, and a slight decrease in that of the women, from age $19 \mathrm{~N}$ to 23 (table 3 ), but then little further change by age 29. Questions were asked about sporting activities, again mainly to examine inter-relationships with the lung function measurements. While some active sportsmen had relatively high values of ventilatory function, the types and levels of activity varied so widely that no firm conclusions could be reached in this small group.

\section{Discussion}

This further extension of the study started in 1962 has shown that in a relatively healthy group of 
young adults most measures of respiratory function reach optimum values in the early 20 s, then change little during the remainder of the decade. This late physiological development, which continues for some years after full stature is reached, is in accordance with findings in other studies (Stebbings, 1971; Brooks and Waller, 1972). Our subjects started off at an advantage, for the prevalence of respiratory symptoms (cough, phlegm, breathlessness) among them was low compared with that in general population samples in the same age range (Colley et al, 1973; Waller et al, 1975). In addition, their smoking habits have been light at all times in comparison with those in the general population.

Although the group is small, it will be of interest to follow the further changes in their lung function in later life and to determine, for example, whether spirometric values eventually decline at rates similar to those reported among groups in other occupations (Howard, 1970; Berry, 1974; Kauffman et al, 1976; Quanjer et al, 1976). In view of the small change seen in our sample up to age 29 , it may be that linear regression models relating lung function values to age should be limited to the age range 30 upwards. It is interesting however, that maximum values were reached earlier in some subjects than in others: those with relatively high values at age 19 changed very little after that, while others continued to improve for a few years. This was particularly true in the case of peak flow, and both in the present series and in others that we have done (Brooks and Waller, 1972; Waller et al, 1975) there have been many instances of young subjects (age 19 or under) who were particularly active in sports or other pursuits demanding maximum ventilation having high flows in relation to their heights. It may be that such activities allow optimum values to be reached at an earlier age, without necessarily affecting the final adult values much. To investigate this further would require extensive longitudinal studies starting within the school years, but such a feature could help to explain the large scatter in ventilatory function often seen within groups of children, even after standardising for height.

One reason for selecting medical students initially was that it would be easy to trace them at any later time once they were qualified. This was proved true, but the very wide dispersion throughout the country and abroad limited the response so far as laboratory measurements of lung function were concerned to about $60 \%$ of the original sample. Although further follow-ups may still be possible, and might even be extended to a greater proportion of the subjects if portable equip- ment was used, it should be emphasised that so far all the measurements have been made using the same types of instruments, in one laboratory, under the direction of the same investigators. In view of the small magnitude of changes within individuals in this study, it is clearly important not to change the instrumentation or procedure in any way. One factor that we could not control readily was the time of day at which measurements were made, and the relatively erratic results for transfer factor may be accounted for in this way, since time of day, eating, and exercise are all known to affect this quantity (Cotes, 1975).

We had included MMF (defined as the flow over the interval from $25 \%$ to $75 \%$ of vital capacity) in the spirometric measurements made on the second and third visits, as this was thought to be a more sensitive measure of early airways obstruction than $\mathrm{FEV}_{1}$ or peak flow. Certainly the contrasts in MMF between subgroups were greater than those in other spirometric observations, but the standard deviations for MMF were about three times those for $\mathrm{FEV}_{1}$, and so it was still not possible to see statistically significant differences. Several workers have reported a wide scatter in measurements such as MMF made near mid-expiration (Minette and Lavenne, 1971; Morris et al, 1971; Newball, 1975; Cochrane et al, 1977), and this is a limitation to its use both in cross-sectional and in longitudinal studies.

One consistent feature has been the tendency for individuals reporting episodes of acute chest illness at any time since birth to have relatively low lung function values as young adults. In the follow-up of the national 1946 birth cohort, the prevalence of respiratory symptoms was determined largely by smoking habits, but beyond that it was higher in subjects with histories of chest illnesses in childhood than in others (Colley et al, 1973; Kiernan et al, 1976). Also, in our study of Londoners born in 1952-3, the factor having the greatest effect on ventilatory function at age 18 to 19 appeared to be a positive history of chest illnesses (Waller et al, 1975). There is thus much evidence of long-term effects of acute chest illnesses contracted during childhood, and the examination of trends in lung function in relation to past illnesses may deserve further attention in longitudinal studies.

We would like to record our appreciation of the willing co-operation of the subjects. Our thanks are also due to our colleagues in the MRC Unit for their help, and particularly to Miss $S$ Brailsford, who was responsible for making many of the measurements. 


\section{References}

Berry, G (1974) Longitudinal observations. Their usefulness and limitations with special reference to the forced expiratory volume. Bulletin de Physiopathologie Respiratoire, 10, 643-656.

Brooks, A G F, and Waller, R E (1972). Peak flow measurements among visitors to a public health exhibition. Thorax, 27, 557-562.

Cochrane, G M, Prieto, F, and Clark, T J H (1977). Intrasubject variability of maximal expiratory flow volume curve. Thorax, 32, 171-176.

Cole, T J (1974). The influence of height on the decline in ventilatory function. International Journal of Epidemiology, 3, 145-152.

Cole, T J (1975). Linear and proportional regression models in the prediction of ventilatory function. Journal of the Royal Statistical Society, A, 138, 297-337.

Colley, J R T, Douglas, J W B, and Reid, D D (1973). Respiratory disease in young adults: influence of early childhood lower respiratory tract illness, social class, air pollution, and smoking. British Medical Journal, 3, 195-198.

Cotes, J E (1975). Lung function: assessment and application in medicine, 3rd edition. Blackwell, Oxford.

Cotes, J E (1976). Serial data over 10-22 years for detailed lung function of working men. Scandinavian Journal of Respiratory Diseases, 57, 316-317.

Ferris, B G, jun, Chen, H, Puleo, S, and Murphy, R L H, jun (1976). Chronic non-specific respiratory disease in Berlin, New Hampshire, 1967-1973. A further follow-up study. American Review of Respiratory Disease, 113, 475-485.

Fletcher, $\mathbf{C} \mathbf{M}$, Peto, R, Tinker, $\mathbf{C} \mathbf{M}$, and Speizer, F E (1976). The Natural History of Chronic Bronchitis and Emphysema. Oxford University Press, London.

Hamilton, M, Pickering, G W, Roberts, J A F, and Sowry, G S C (1954). The aetiology of essential hypertension. 1 . The arterial pressure in the general population. Clinical Science, 13, 11-35.

Higgins, M W, and Keller, J B (1973). Seven measures of ventilatory lung function. Population values and their ability to discriminate between persons with and without chronic respiratory symptoms and disease, Tecumseh, Michigan. American Review of Respiratory Disease, 108, 258-272.

Howard, P (1970). A long-term follow-up of respiratory symptoms and ventilatory function in a group of working men. British Journal of Industrial Medicine, 27, 326-333.

Kauffmann, F, Brille, D, and Lellouch, J (1976). Factors related to FEV 1 slope between two crosssectional surveys, 1960-72. Scandinavian Journal of Respiratory Diseases, 57, 313-316.
Kiernan, K E, Colley, J R T, Douglas, J W B, and Reid, D D (1976). Chronic cough in young adults in relation to smoking habits, childhood environment and chest illness. Respiration, 33, 236-244.

Lawther, P J, Brooks, A G F, and Waller, R E (1970). Respiratory function measurements in a cohort of medical students. Thorax, 25, 172-177.

Lee, P N (1976). Statistics of smoking in the United Kingdom, 7th edition. Tobacco Research Council, London.

Lowe, C R, Pelmear, P L, Cambell, H, Hitchens, R A N, Khosla, T, and King, T C (1968). Bronchitis in two integrated steel works. 1. Ventilatory capacity, age and physique of non-bronchitic men. British Journal of Preventive and Social Medicine, 22, 1-11.

Medical Research Council (1966). Questionnaire on respiratory symptoms. Now replaced by 1976 version. Medical Research Council, London.

Minette, A, and Lavenne, F M (1971). Reproducibility of respiratory function tests applicable to epidemiologic surveys of bronchitis. Revue de l'Institut d'Hygiene des Mines (Hasselt), 26, 63-72.

Morris, J F, Koski, A, and Johnson, L C (1971). Spirometric standards for healthy non-smoking adults. American Review of Respiratory Disease, $103,57-67$.

Newball, H H (1975). The unreliability of the maximal mid-expiratory flow as an index of acute airways changes. Chest, 67, 311-314.

Oxhoj, H, Bake, B, and Wilhelmsen, L (1976). Spirometry and flow-volume curves in 10-year follow-up in men born 1913. Scandinavian Journal of Respiratory Diseases, 57, 310-312.

Quanjer, P H, van der Maas, L J, van Hartevelt, J H, and van der Lende, R (1976). Maximal expiratory flow-volume curves in a follow-up study. Scandinavian Journal of Respiratory Diseases, 57, 309-310.

Stebbings, J M, jun (1971). Chronic respiratory disease among non-smokers in Hagerstown, Maryland. II. Problems in the estimation of pulmonary function values in epidemiological surveys. Environmental Research, 4, 163-192.

Waller, R E, Brooks, A G F, and Adler, M (1975). Respiratory symptoms and ventilatory capacity in a cohort of Londoners born in 1952-53. International Symposium: Recent advances in the assessment of the health effects of environmental pollution. Proceedings, 1, 77-90. Commission of the European Communities, Luxembourg.

Requests for reprints to: Professor P J Lawther, MRC Toxicology Unit (Clinical Section), St Bartholomew's Hospital Medical College, Charterhouse Square, London EC1M 6BQ. 